\title{
Simultaneous Study of VLF/ULF Anomalies Associated with Earthquakes in Japan
}

\author{
Vikram Singh" ${ }^{1}$, Yasuhide Hobara ${ }^{2}$ \\ ${ }^{1}$ Department of Physics, St. John's College, Agra, India \\ ${ }^{2}$ Graduate School of Informatics and Engineering, University of Electro-Communications, Chofu, Tokyo, Japan \\ Email: hobara@ee.uec.ac.jp
}

How to cite this paper: Singh, V. and Hobara, Y. (2020) Simultaneous Study of VLF/ULF Anomalies Associated with Earthquakes in Japan. Open Journal of Earthquake Research, 9, 201-215.

https://doi.org/10.4236/ojer.2020.92012

Received: March 14, 2020

Accepted: March 28, 2020

Published: March 31, 2020

Copyright $\odot 2020$ by author(s) and Scientific Research Publishing Inc. This work is licensed under the Creative Commons Attribution International License (CC BY 4.0).

http://creativecommons.org/licenses/by/4.0/ (c) (i) Open Access

\begin{abstract}
We carried out a simultaneous study of ground-based magnetic field and lower ionospheric anomalies during major earthquakes occurring around Japan in 2010 and 2012. Ultra Low Frequency (ULF) geomagnetic field waveforms of Esashi station and Very Low Frequency (VLF) Japanese transmitter (JJY) electric signal amplitude received in Moshiri station Hokkaido during nighttime (22:00-02:00 LT) were used to minimize the local interference. Twenty earthquakes having magnitude greater than 5.5 were considered for the data analysis for two years. Nighttime amplitude fluctuations and polarization from the received VLF transmitter signal amplitude and ULF magnetic field respectively were calculated to identify anomalous signatures in relation to every earthquake. We found most earthquakes analyzed indicating VLF amplitude anomalies simultaneously occurred with ULF magnetic field anomalies within a week prior to the earthquakes. Stronger anomalies were observed for larger magnitude and shallower earthquakes. Focal mechanism of earthquakes was also examined to identify the effectiveness of generating anomaly. Both VLF and ULF anomalies were observed for reverse fault type earthquakes occurring under the strong pressure in the crust. Obtained results may indicate the common anomaly source both for VLF and ULF in the lithosphere and are consistent with currently proposed Lithosphere-Atmosphere-Ionosphere (LAI) coupling scenarios during the earthquake preparation period.
\end{abstract}

\section{Keywords}

VLF Transmitter, Ionosphere, Perturbations, ULF, VLF, Anomalies, Earthquake, Geomagnetic Field, Focal Mechanism, Precursor

\section{Introduction}

Considering the global concern of the effect of earthquake disaster, studies of 
earthquake prediction are in progress globally using different methods and technologies. Earthquake prediction study is still very complex and needs many serious efforts not only to achieve its high accuracy but also to understand mechanism of precursory signatures. Among various research fields, monitoring electromagnetic emissions and ionospheric perturbations prior to the earthquakes has proved its worth by showing some positive results for the earthquake precursors. Electromagnetic emissions in relation to major seismic activities from DC to HF range have been detected using numerous ground and space-based experiments [1]-[15]. Although individual seismo-electromagnetic parameters have shown their success to identify precursors, a considerable amount of false seismogenic anomalies are presumably due to other geophysical phenomena and local interferences. Therefore monitoring of different electromagnetic parameters has been proposed recently to enhance the success rate of identifying seismogenic anomalies [16] [17] [18].

Among many seismo-electromagnetic parameters, anomalous signatures of ULF magnetic field and VLF transmitter amplitude during the seismic activities have been found much promising for earthquake prediction purpose. Studies of ULF magnetic field anomalies during the seismic activities have been reported by using different methods such as amplitude anomaly method, polarization parameter method, fractal analysis method etc. [5] [19] [20] [21] [22] [23]. These methods are based upon the assumption that the anomalous ULF field is generated by the current source around the earthquake preparation region. In recent years, a new method has been proposed so-called depression method [24]. In this method, amplitudes of ULF waves penetrated from magnetosphere are monitored. Depressions in ULF magnetic field in the frequency range from 0.3 to $0.5 \mathrm{~Hz}$ were found before earthquakes presumably due to the attenuation of ULF waves during the propagation through the perturbed ionosphere [25].

Seismo-ionospheric perturbations are monitored by subionospheric VLF transmitter signals. Amplitude reduction method and terminator time method are in use but producing ambiguous results [13] [17] [26]. The reduction method was further refined by trend and nighttime fluctuation methods [27]. In spite of using rather sophisticated data analysis, there are still false seismogenic anomalies because of many perturbation sources of the lower ionosphere other than seismogenic ones such as space weather and atmospheric parameters [28] [29]. Therefore, multi-parameter observations are promising to identify the seismo-electromagnetic signals more accurately rather than observations of single parameter.

In this study we carry out the simultaneous study of anomalies observed by ULF magnetic field and VLF transmitter signals in relation to major earthquakes occurring in Japan in the years of 2010 and 2012. We also try to study the physical mechanism of anomalies for analyzed earthquakes inferred from types of earthquakes determined by their focal mechanism.

\section{Observational Data and Analysis}

We use the VLF signal amplitude continuously received at Moshiri $(40 \mathrm{kHz})$ (la- 
titude $44.4^{\circ} \mathrm{N}$, longitude $142.3^{\circ} \mathrm{E}$ ), Hokkaido emitted from JJY transmitter in Fukushima (latitude $37.37^{\circ} \mathrm{N}$, longitude $140.85^{\circ} \mathrm{E}$ ) to monitor the lower ionospheric conditions. Geomagnetic field data in ULF range from Esashi geomagnetic observatory (latitude $39.23^{\circ} \mathrm{N}$, longitude $141.35^{\circ} \mathrm{E}$ ) in Iwate are used because Esashi station is situated around the great circle path (GCP) between JJY and Moshiri (JJY-MSR path). Then we study lower ionospheric and geomagnetic anomalies associated with major earthquakes occurred around JJY-MSR path.

VLF subionospheric perturbations have been continuously monitored by the network observation operated by the University of Electro-Communications, Tokyo, Japan. The years of data analysis are 2010 and 2012. We excluded the data of 2011 because of several long data gaps due to the power failure associated with the 2011 earthquake off the Pacific coast of Tohoku. We analyzed the VLF transmitter amplitude data using nighttime fluctuation method [27]. In this method, the trend value of nighttime amplitude was calculated by subtracting the running average of the last 15 days of averaged nighttime amplitude from the daily nighttime average amplitude from 22:00 to 02:00 LT.

The ULF data of Esashi station was obtained from its website www.vldb.gsi.go.jp. We used the 3-component ( $H_{\mathrm{x}}$ : North-South, $H_{\mathrm{y}}$ : East-West, and $H_{\mathrm{z}}$ : Vertical) magnetic field waveform data of $1 \mathrm{~Hz}$ sampling rate. The power spectral density for three components $\left(P_{x}, P_{y}\right.$, and $\left.P_{z}\right)$ were calculated by using Fast Fourier Transform (FFT) between 0.0017 and $0.5 \mathrm{~Hz}$. Furthermore, we calculated polarizations $P_{\mathrm{z}} / P_{\mathrm{x}}$ and $P_{\mathrm{z}} / P_{\mathrm{y}}$ using its horizontal and vertical components for different frequency bands. This parameter has been found to increase before earthquakes (started from a few weeks before an earthquake) as reported by [20] [23]. Magnetic Indices data and earthquake data were obtained from www.wdc.kugi.kyoto-u.ac.jp and www.earthquake.usgs.gov respectively. We consider the earthquakes with magnitude greater than 5.5 and depth less than $200 \mathrm{~km}$ for our data analysis. Furthermore, we took a spatial limitation by choosing epicenters located within the first Fresnel zone of JJY-Moshiri for VLF data analysis or within the circle of radius $300 \mathrm{~km}$ around the Esashi station for ULF data analysis shown in Figure 1 and Figure 4.

\section{Results and Discussion}

In 2010, 5 earthquakes occurred within the first Fresnel zone (events 1, 2, 4, 6, and 8) of JJY-MSR VLF transmitter-receiver path. Detailed information of 8 earthquakes analyzed are given in Table 1. In Figure 2, we present the VLF data during the year of 2010. The top panel shows daily variation of trend value normalized by running standard deviation $\sigma$ of the trend using previous 15 days, and $\Sigma \mathrm{Kp}$ index is also plotted in the bottom panel of the figure.

Vertical lines in Figure 2 show the occurrence days of the earthquakes, and the event numbers of the earthquakes are given at the top of each line. Centroid Moment Tensor (CMT) solution of each earthquake is also shown in the third panel. The CMT solution indicates the relation between the six independent parameters of moment tensor representation of earthquake and ground motion 


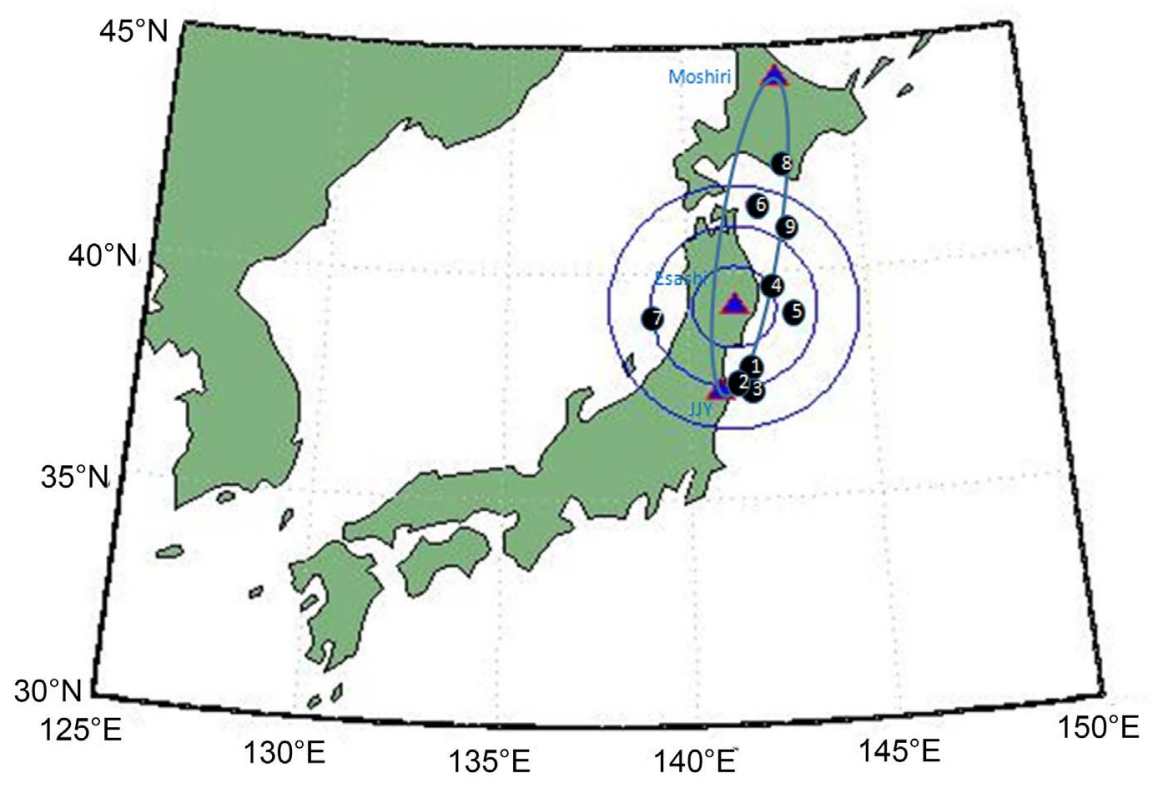

Figure 1. Black circles with a number show the location of earthquakes occurred in 2010, triangles show the locations of VLF transmitter (JJY), receiver (Moshiri) and ULF magnetic field observatory (Esashi), three concentric circles show the distances from the Esashi station of 100, 200 and $300 \mathrm{~km}$.

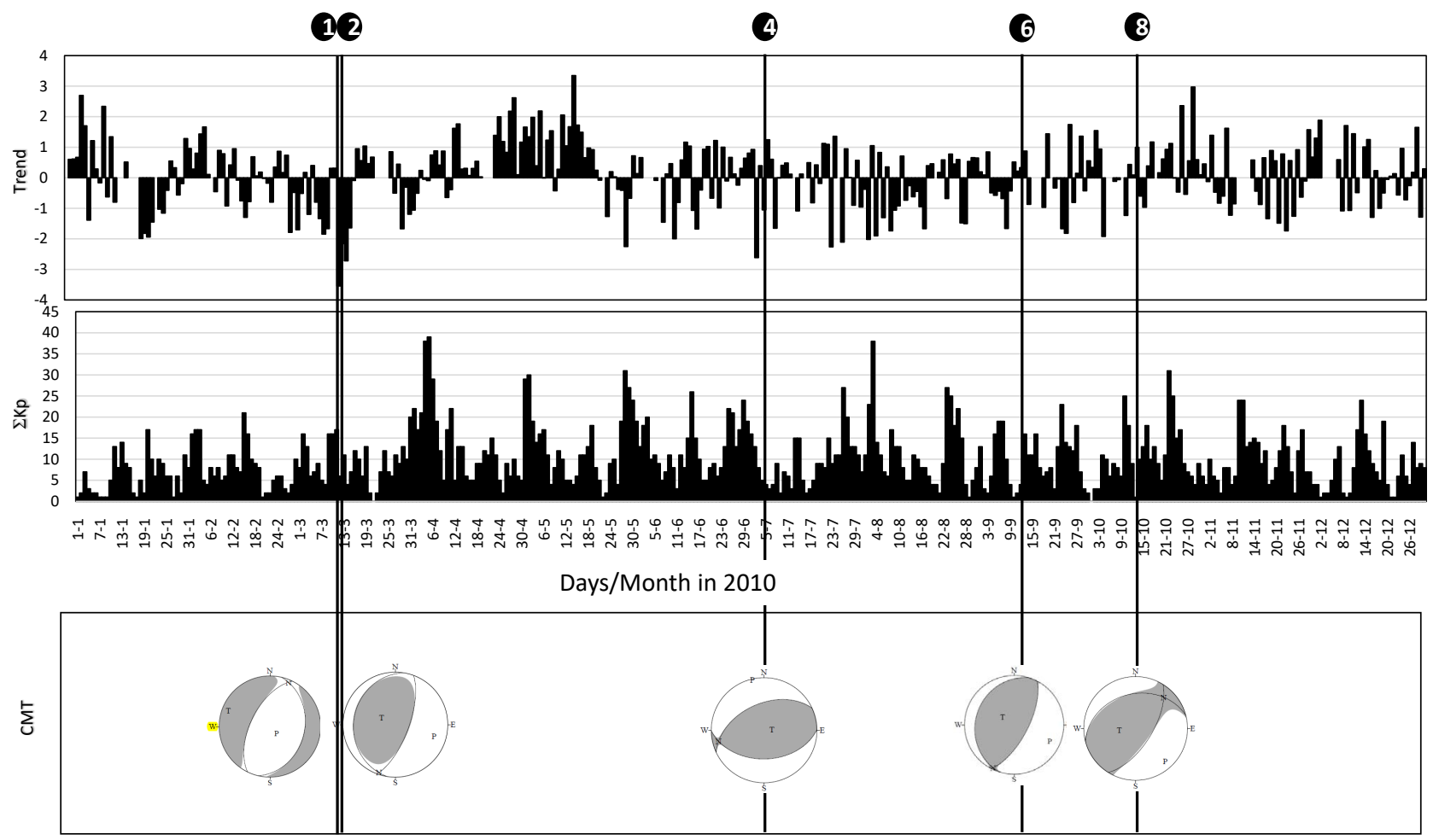

Figure 2. Top panel shows the normalized nighttime VLF amplitude (trend) by running standard deviation, middle and bottom panels show the $\Sigma \mathrm{Kp}$ and CMT solution respectively for 2010 .

that earthquake generates [30] [31]. This solution provides the information about the motion of plates causing the earthquake, which leads to the type of 
Table 1. Details of earthquake parameters for 2010. Shadowed events occurred within the first Fresnel zone of the JJY-MSR VLF transmitter-receiver path.

\begin{tabular}{ccccccc}
\hline No. & Date & Lat. & Long. & Mag. & Depth & EQ Types \\
\hline 1 & $13-03-2010$ & 37.594 & 141.299 & 5.6 & 76.7 & Normal \\
2 & $14-03-2010$ & 37.745 & 141.59 & 6.5 & 32 & Reverse \\
3 & $13-06-2010$ & 37.372 & 141.625 & 5.9 & 27 & \\
4 & $05-07-2010$ & 39.697 & 142.369 & 6.3 & 27 & Reverse \\
5 & $10-08-2010$ & 39 & 143 & 5.9 & 33 & \\
6 & $13-09-2010$ & 41.497 & 141.986 & 5.8 & 45 & Reverse \\
7 & $29-09-2010$ & 39 & 139 & 5.5 & 33 & \\
8 & $14-10-2010$ & 42.311 & 142.871 & 5.6 & 59 & Reverse \\
9 & $06-12-2010$ & 40.904 & 142.967 & 5.7 & 22 & \\
\hline
\end{tabular}

earthquakes indicated in Table 1. The trend value of VLF shows a significant decrease within 7 days prior to all 5 earthquakes. In particular, the trend decreases of more than $2 \sigma$ (i.e. the value-2 in the top panel in Figure 2) before the occurrence of the earthquakes 2 and 4 , and the trend decreases around $1.5 \sigma$ (i.e. -1.5 in the vertical axis) before the earthquakes 1, 6 and 8. It can be seen from Table 1 that magnitudes of the earthquakes 2 and 4 are greater than 6 and depth less than $35 \mathrm{~km}$, while the magnitudes of earthquakes 1,6 and 8 are less than 6 and depth greater than $35 \mathrm{~km}$. However, there are cases when amplitude anomalies (a significant decrease in trend value) occurred without seismic activities as shown in Figure 2, the reasons of these anomalies may be due to the factors other than seismic activities such as the effect of global geomagnetic disturbance originated from solar activity and atmospheric phenomena toward the lower ionosphere as reported by [28] [29].

To examine the seismo-electromagnetic effects different from VLF anomaly for these earthquakes, ULF magnetic field data observed at Esashi station (located within the first Fresnel zone of the JJY-MSR path) were analyzed using polarization method. We calculated power spectral density $\left(P_{\mathrm{x}}, P_{\mathrm{y}}\right.$, and $\left.P_{\mathrm{z}}\right)$ and then obtained two polarizations $P_{\mathrm{z}} / P_{\mathrm{x}}$ and $P_{\mathrm{z}} / P_{\mathrm{y}}$ for two frequency ranges MP3 $(3.3-6.7 \mathrm{mHz})$ and MP5 $(10-22 \mathrm{mHz})$ in 2010 for the earthquakes shown in Table 1.

Figure 3 shows the normalized polarizations $\left(\left(P_{\mathrm{z}} / P_{\mathrm{x}}-m\right) / \sigma\right.$ and $\left(P_{\mathrm{z}} / P_{\mathrm{y}}-\right.$ $m) / \sigma)$ ) greater than 0 (i.e. greater than the mean value of polarization in both frequency ranges in the first four panels. The fifth panel shows the variation of $\Sigma \mathrm{Kp}$ indicating global geomagnetic activity. In this figure we can see many spikes, i.e. large increases in the normalized polarizations, during the time period of analysis. And these spikes occurred not only around the earthquakes. However, if we focus on the time period around the timings of the earthquakes, most earthquakes (events 1, 2, 3, 5, 6, 7 and 9) show the significant magnetic field anomalies (at least one of the normalized polarizations is greater than 2 


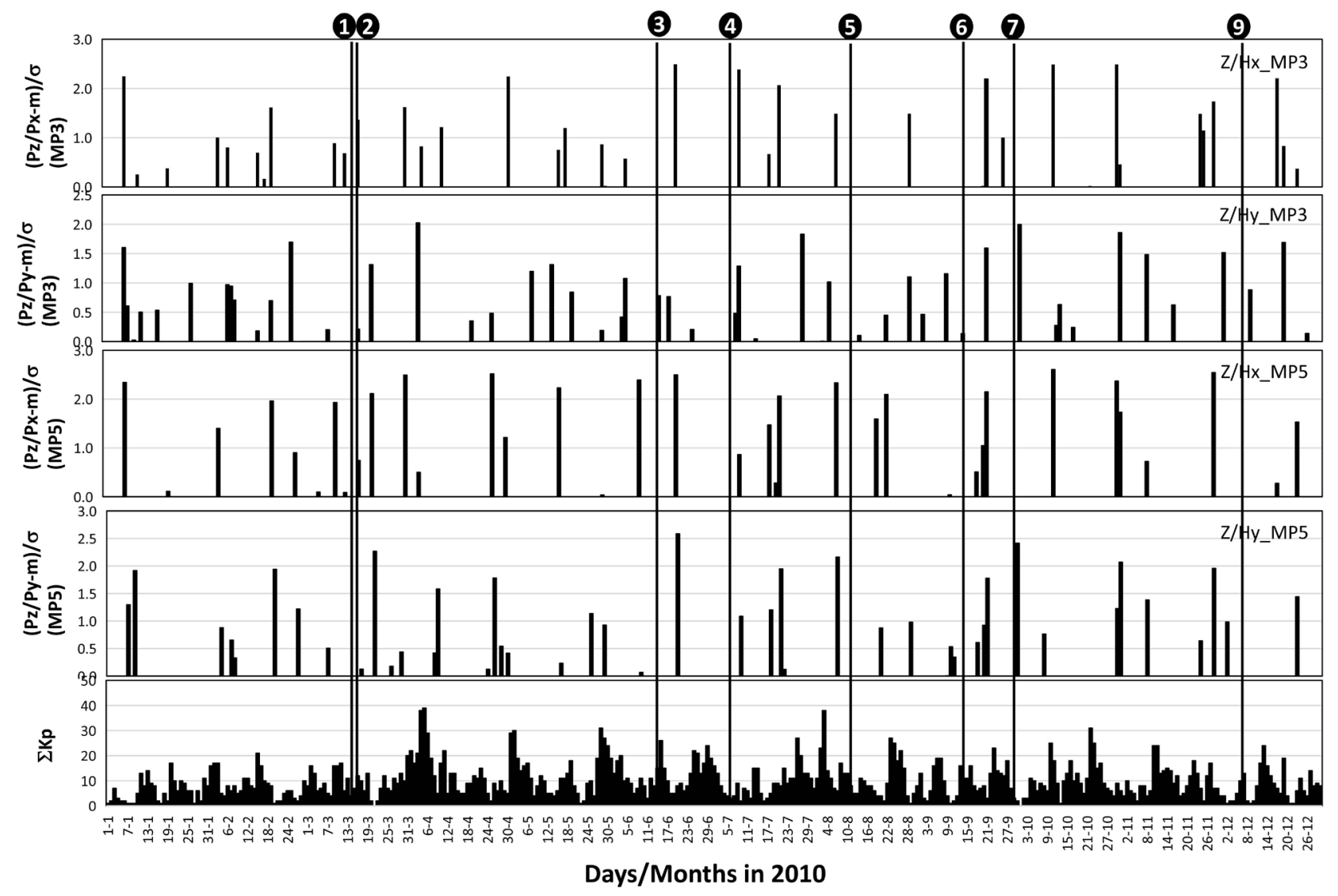

Figure 3. Summary of the results from polarization analysis of ULF magnetic field in 2010. Four panels from the top show the variations of polarizations $\left(\left(P_{\mathrm{z}} / P_{\mathrm{x}}-m\right) / \sigma\right.$ and $\left.\left.\left(P_{\mathrm{z}} / P_{\mathrm{y}}-m\right) / \sigma\right)\right)$ for two frequency bands MP3 and MP5 respectively. Fifth panel shows the variation of $\Sigma \mathrm{Kp}$ index.

within about one week before the earthquake). Earthquake event 4 does not show any clear anomaly despite its proximity to the ULF observation station and relatively large magnitude. The earthquake event 7 has a large polarization but it occurred 8 days before the earthquake, which is the longest lead time among 7 earthquakes with an anomaly. In this figure, epicenters of four earthquakes (events 3, 5, 7 and 9) do not lie in the Fresnel zone of JJY-Moshiri, but the ULF anomaly was identified within the circle of radius of $300 \mathrm{~km}$ around Esashi station as shown in Figure 1.

Now we compare the results between VLF and ULF data analysis. All 5 earthquakes within the first Fresnel zone of the VLF path indicate anomalies. Among them, 4 earthquakes show anomalies in the ULF magnetic field. Anomalies both in VLF and ULF occurred within about a week before earthquakes despite lead time varies between earthquakes but occurred the similar timings between VLF and ULF. This simultaneous occurrence both in time and spatial coordinates may indicate that observed anomalies in VLF and ULF are from the same seismogenic origin and also indicate LAI-coupling if the source of ULF field anomalies is originated in the lithosphere. However, many ULF anomalies were identified during 2010 other than earthquake timings and occurred more frequently 
than those of VLF. ULF magnetic field is perturbed by many external forcing effects including global geomagnetic activity, interferences from human activities in addition to the local seismicity.

Furthermore, magnitude of VLF anomaly (trend) has a qualitative relationship with earthquake parameters. For example, two large earthquakes (evets 2 $(M=6.5)$ and $4(M=6.3))$ show large anomalies greater than $-3 \sigma$ with relatively small depth, and other events have much smaller anomalies with smaller magnitude and large depth. Whilst, the magnitude of ULF anomaly (polarization) does not clearly show the qualitative relation with earthquake parameters such as magnitude, distance from epicenter. For example, earthquake event 4 is a reverse type (we explain later why this earthquake type is important) with a large magnitude and shallow epifocus. Moreover this event occurred at the shortest distance from the ULF station during moderate $\Sigma \mathrm{Kp}$, so that a large anomaly is expected but the magnetic field does not show any clear anomaly in contrast to VLF. We have not found a reasonable explanation yet and we have to investigate this.

Finally, we focus on the CMT solution for an earthquake, almost all earthquakes analyzed in 2010 were reverse fault type except event 1 . The event 1 is a normal type earthquake and occurred one day before the event 2 of a reverse type with much larger magnitude. Therefore, the observed anomaly would be due to the reverse type; however we are not able to clearly identify which earthquake is responsible for the observed anomalies. Nevertheless, both VLF and ULF anomalies occur for reverse type earthquakes for majority of earthquake events.

Same type of data analysis was carried out for the year of 2012. In 2012, 8 earthquakes occurred within the first Fresnel zone of JJY-MSR path (events 1, 2, $6,7,8,9,10,11$ ) (Figure 4). And earthquake events 3, 4, and 5 occurred beyond the first Fresnel zone but were located the distance within $300 \mathrm{~km}$ from Esashi ULF observation station. Details of the earthquake parameters are summarized in Table 2.

In Figure 5, we present the results of VLF data analysis for 2012. The top panel shows daily variation of nighttime amplitude deviation from running mean normalized by running standard deviations, and $\Sigma \mathrm{Kp}$ index is also plotted in the second panel of the figure. In the bottom panel, CMT solution is shown. Earthquakes events 2 shows a significant decrease (i.e. anomaly) in the trend greater than $2 \sigma$, while events $6,8,9$, and 10 show the decrease less than $2 \sigma$ but greater than $1.5 \sigma$. And these anomalies occurred up to 7 days before the earthquakes. The earthquake event 7 does not show any clear anomaly. From Figure 6 we can see that many earthquakes show significant anomaly on ULF magnetic field. The earthquake events $1,2,3,4,5,8$, and 11 show the enhancement in polarization greater than $2.5 \sigma$, while events 6,7 and 10 do not show clear ULF anomalies.

Comparing the results between VLF and ULF, earthquake event 2 is the 2nd largest magnitude of $\mathrm{M}=6.1$ and also shallow $(\mathrm{D}=15 \mathrm{~km})$ in Table 2 and so it 
Table 2. Details of earthquake parameters for 2012. Shadowed events occurred within the first Fresnel zone of the JJY-MSR VLF transmitter-receiver path.

\begin{tabular}{ccccccc}
\hline No & Date & Lat & Long & Mag & Depth & EQ Types \\
\hline 1 & $28-01-2012$ & 40.177 & 142.211 & 5.6 & 55.3 & Reverse \\
2 & $27-03-2012$ & 39.859 & 142.017 & 6.1 & 15 & Reverse \\
3 & $01-04-2012$ & 37.116 & 140.957 & 5.7 & 48 & \\
4 & $12-04-2012$ & 37.513 & 141.468 & 5.5 & 25.1 & \\
5 & $13-04-2012$ & 36.988 & 141.152 & 5.7 & 11 & \\
6 & $30-04-2012$ & 39.745 & 142.037 & 5.6 & 10 & Normal \\
7 & $23-05-2012$ & 41.335 & 142.082 & 5.9 & 46 & Reverse \\
8 & $17-06-2012$ & 38.919 & 141.831 & 6.3 & 36 & Reverse \\
9 & $25-08-2012$ & 42.419 & 142.913 & 5.9 & 54.5 & Normal \\
10 & $29-08-2012$ & 38.425 & 141.814 & 5.5 & 47.4 & Reverse \\
11 & $25-10-2012$ & 38.306 & 141.699 & 5.6 & 55.7 & Reverse \\
\hline
\end{tabular}

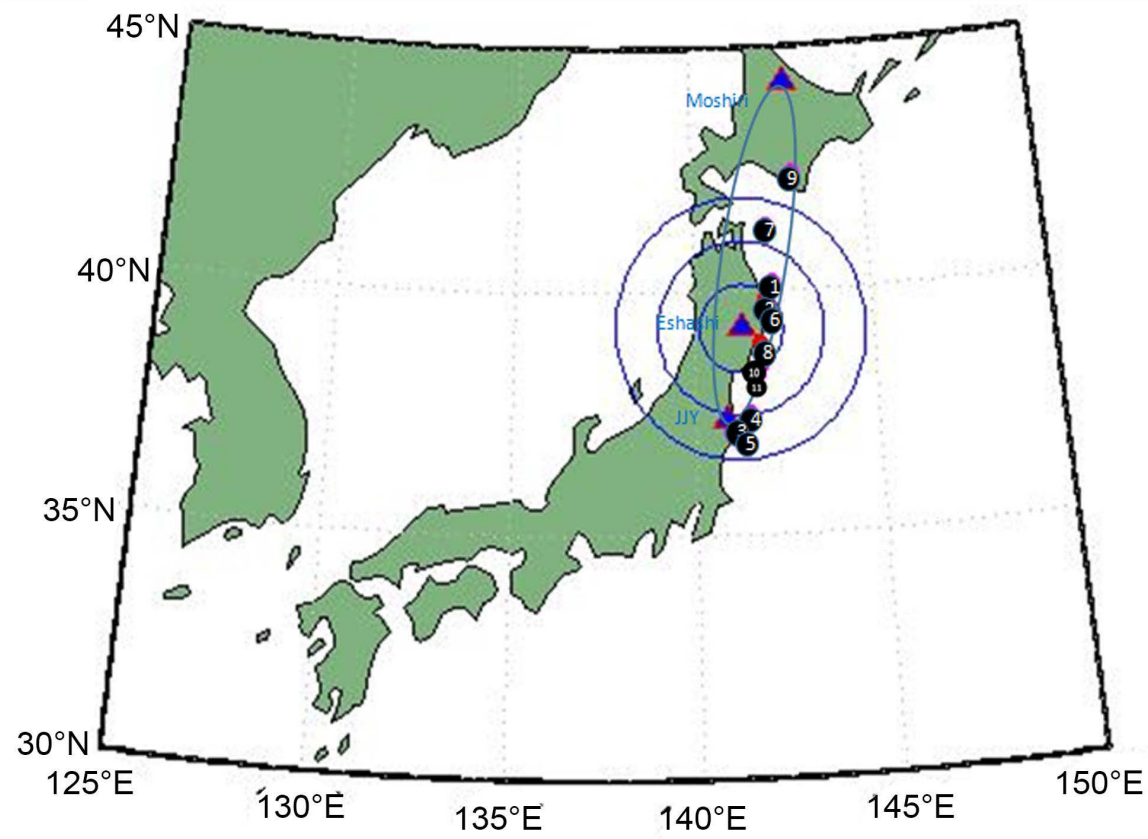

Figure 4. Black circles with a number show the location of earthquakes occurred in 2012, triangles show the locations of VLF transmitter (JJY), receiver (Moshiri) and ULF magnetic field observatory (Esashi), three concentric circles show the distances from the Esashi station of 100, 200 and $300 \mathrm{~km}$.

is understandable that a large anomaly was observed both in VLF and ULF because large energy was accumulated close to the ground within the earthquake preparation region. On the other hand, earthquake event 7 does not show significant anomaly both in VLF and ULF. Possible reason for this may be due to the epicenter located under the sea away from the coast and to depth being not shallow $(46 \mathrm{~km})$, which make it difficult for anomalous ULF field generated 


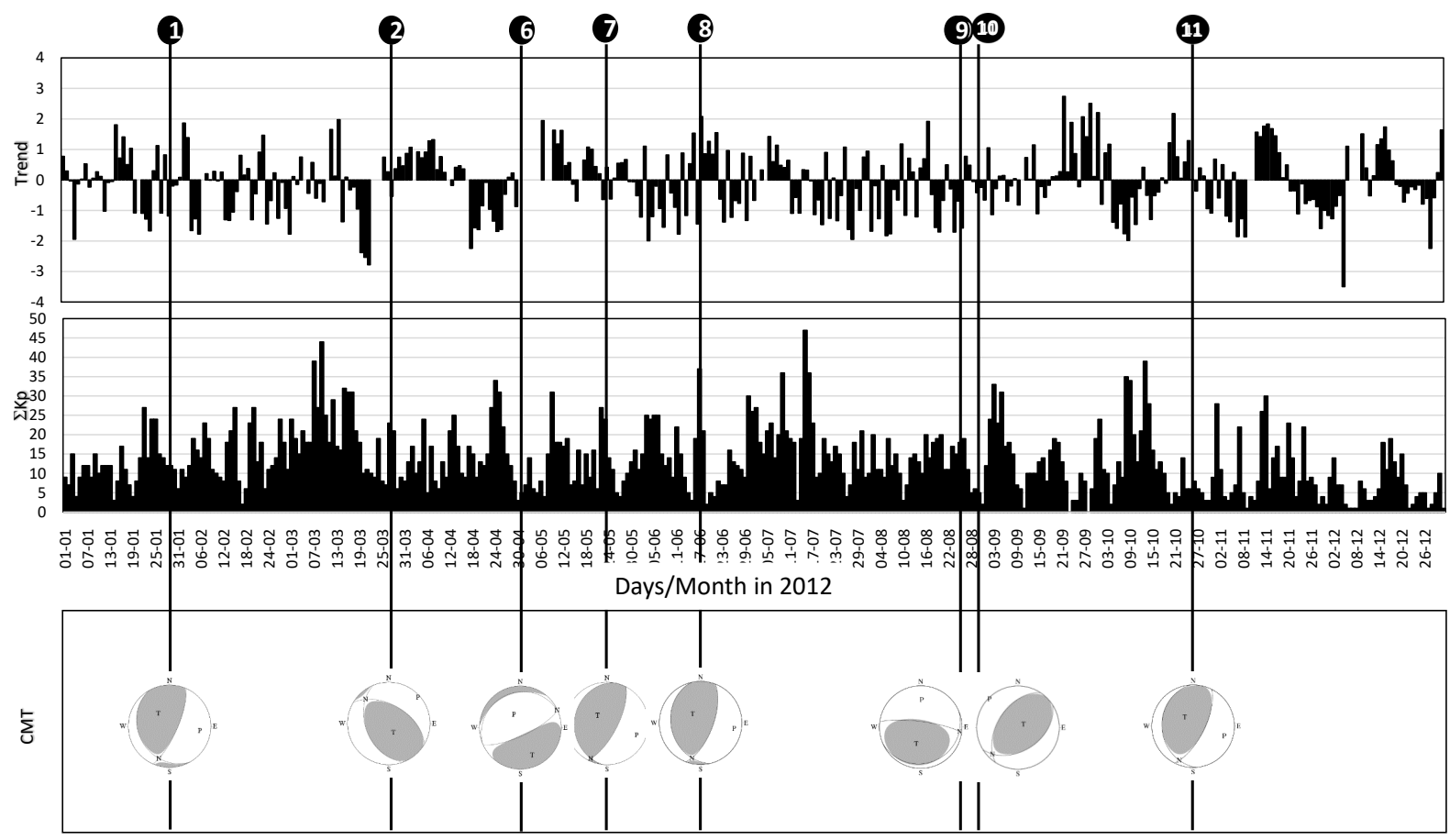

Figure 5. Top panel shows the normalized nighttime VLF amplitude (trend) by running standard deviation, middle and bottom panels show the $\Sigma \mathrm{Kp}$ and CMT solution respectively for 2012.

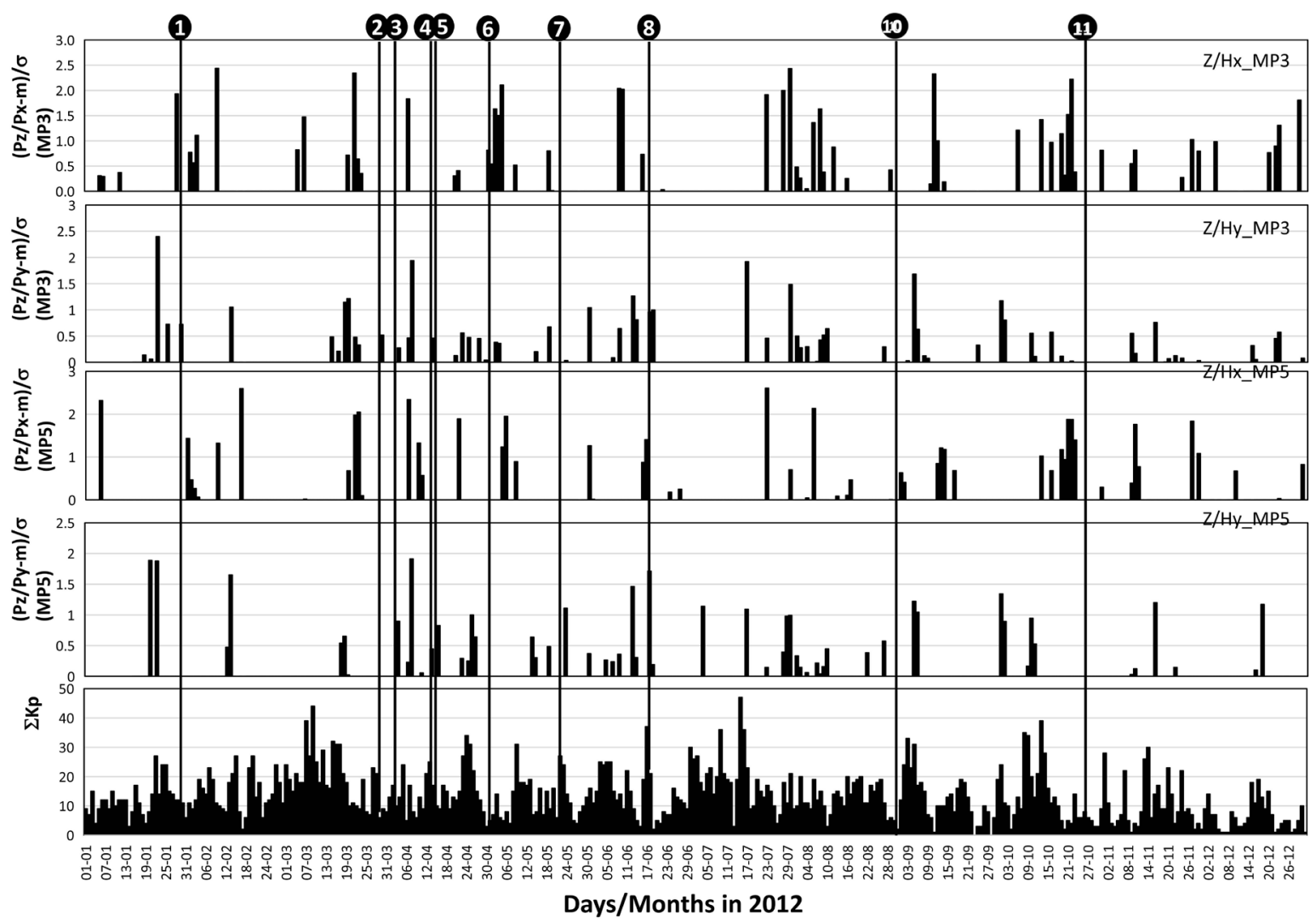

Figure 6. Summary of the results from polarization analysis of ULF magnetic field in 2012. Four panels from the top show the variations of polarizations $\left(\left(P_{\mathrm{z}} / P_{\mathrm{x}}-m\right) / \sigma\right.$ and $\left.\left.\left(P_{\mathrm{z}} / P_{\mathrm{y}}-m\right) / \sigma\right)\right)$ for two frequency bands MP3 and MP5 respectively. Fifth panel shows the variation of $\Sigma \mathrm{Kp}$ index. 
around epifocus penetrating through the deep water over the epicenter. Although some other earthquakes also occurred underwater, they are very close to coastal area and so an anomaly appeared on the ground without significant attenuation. In the event 6 , the anomaly in VLF occurred continuously for a few days around 1 week before the earthquake was identified but not in ULF. This VLF anomaly may be due to global geomagnetic disturbance inferred from rather high $\Sigma \mathrm{Kp}$ as previously reported [28] and the local seismo-magnetic effect was masked. Overall, half of the earthquakes have a correlation between VLF and ULF anomalies except high $\Sigma$ Kp period (event 6). Three events (1,2 and 8) show anomaly and one event (7) does not show anomaly both in VLF and ULF. Either VLF or ULF anomaly is observed for two earthquakes (10 and 11). Regarding event 10, observed anomaly in VLF can be due to event 9 rather than event 10, because the epicenter of the event 9 is in the VLF path but far from the ULF station $(>300 \mathrm{~km})$, which occurred 4 days before event 10 and ULF does not show anomaly for event 10 . The reason why no anomaly observed for the event 11 in VLF can be due to the epicenter being located at the edge of the first Fresnel zone, while ULF anomaly was identified because of proximity of the ULF observation station.

We also examined CMT solution for these earthquakes and found these two earthquake events 6 and 9 are normal type earthquakes while other events indicate reverse type(s). The earthquake event 6 occurred during high $\Sigma \mathrm{Kp}$ time period and VLF and ULF variations were affected. For the event 9, VLF anomaly was identified probably for the normal type of earthquake. Because of lack of numbers of normal type earthquakes and, we are not able clarify if normal type earthquake is effective to generate anomalies as the reverse type earthquake.

In this study we have made an effort to examine anomalies occurred prior to major earthquakes based upon the ULF geomagnetic field and remotely received VLF transmitter electric amplitude indicating lower ionospheric perturbations. During the about one week period before earthquakes, both ULF/VLF anomalies were found simultaneously for majority of earthquakes. Earthquakes with larger magnitude and small depth tend to show a stronger anomaly. However, ULF has many anomalies unrelated to earthquakes than VLF during the time period of analysis. These non-seismogenic anomalies are possibly due to other external forcing factors such as both natural and artificial noises affecting the geomagnetic field. Hence anomalies in ULF seem to be less correlated with seismic activities than those in VLF. On the other hand some earthquakes do not show clear anomalies, which may be due to other parameters such as global geomagnetic disturbance causing the anomaly in VLF amplitude but reducing ULF polarization (i.e. horizontal magnetic components tend to increase during high $\Sigma \mathrm{Kp}$ ). There are other possible reasons why no significant anomalies were observed for some earthquakes during geomagnetically quiet time period. Then we use the focal mechanism of the occurrence of all the earthquakes using CMT solution. 
The type of earthquakes is classified as reverse, normal and strike slip types on the basis of the motion between two tectonic plates. In normal type earthquakes, plates are being moved away from each other and hence less pressures in the crust are expected for deformation. Plates are slipped to each other in slip type and some pressure is expected in this case. On the other hand, for a reverse type, plates are supposed to push with each other and maximum pressures are expected among the three types of earthquakes. Since generation of electromagnetic energy during the earthquakes process depends upon the pressure [32] [33]. We can consider that much larger energy is released in reverse type of earthquakes in comparison to other two types if magnitudes being similar, which is responsible to modify the ionosphere causing the perturbation in electric amplitude of VLF transmitter propagating through the earth-ionosphere waveguide. The proposed mechanisms for the generation of electric and magnetic fields during crustal deformation and earthquakes are due to pressure-induced piezoelectric effect, tribo-electric effect, electro-kinetic effect and micro fracturing which lead to the generation of seismogenic ULF and VLF electromagnetic waves which can be directly monitored from ground based systems [33] [34].

Now for explaining the LAI coupling during the seismic activities, some physical scenarios are proposed; first possibility is that the radon gas emanated from the seismic regions propagated upward and created inhomogeneity in the electron density at the base of the ionosphere in the form of localized enhancement. The observations of intensified radioactive gas emanations before the earthquakes have already been reported e.g. [35]. This mechanism is also applicable for the ionospheric disturbances during the earthquake occurring under the sea. In addition to the above mentioned mechanism, there is another possibility in which the ionosphere perturbation is caused by seismic activities. This is related to the electric fields generated from the highly pressurized EQ preparation region which may penetrate through the lower ionosphere and modify the ionospheric layer by a few kilometers so that the phase and amplitude of the subionospheric VLF signals are influenced [26]. But this effect may not work effectively for the earthquakes occurred under the deep water.

The other possibility could be the generation of long period gravity waves during the earthquake preparation process and their intensification at the base of the ionosphere. This possibility has been discussed by [15] [16] in great detail. Above mentioned coupling scenarios are almost verified from our experimental results in which most of the reverse type earthquake are showing anomalies both in VLF and ULF simultaneously, while the normal type may not show clearly as seen from the 5-year statistical study [36]. Furthermore, most VLF anomalies (i.e. lower ionospheric perturbations) are observed almost simultaneously with ULF magnetic anomalies, which indicates rather clear LAI coupling process for seismic preparation process.

Finally, multi-parameter approach such as simultaneous observations of VLF amplitude and ULF polarization having taken in this paper contributes not only 
to shed light on the generation and propagation mechanism of the precursory anomaly signatures of earthquakes but also enhances the accuracy of precursor identification because these two parameters are physically independent in general, and so spatial extent of anomaly detection and source of interferences (except global geomagnetic activity) are different. Therefore, we are able to validate the anomalies by comparing both VLF and ULF results.

\section{Conclusion}

We have presented the simultaneously analyzed results of ULF magnetic field data and VLF subionospheric propagation data for the years of 2010 and 2012 in relation to major earthquakes around Japan. We found that most earthquakes occurring within the first Fresnel zone show a decrease in VLF amplitude (i.e. ionospheric perturbations) within a week before. ULF magnetic field has more non-seismogenic anomalies than VLF. However the majority of the earthquakes located $<300 \mathrm{~km}$ from the ULF observation station are associated with ULF geomagnetic anomalies as well. Both VLF and ULF anomalies get stronger for larger magnitude and shallower earthquakes. Furthermore, many of these earthquakes with anomalies occurred under strong pressure from reverse fault type earthquakes that were determined by the CMT solution. These results indicate sharing the causative sources generating anomalies in the lithosphere during the earthquake preparation process and are consistent with existing LAI coupling scenarios. Finally, simultaneous observations of ULF and VLF data may enhance the accuracy of precursor identification.

\section{Acknowledgements}

The authors are grateful to World Data Center for Geomagnetism, Kyoto, Japan metrological agency, US Geological Survey, USA and Geomagnetic Survey Institute, Japan for providing data. Authors also thank Prof. B. Singh for useful discussions. This work is partially supported by special management expenses grants for national University corporations (for projects) from the Ministry of Education, Culture, Sports, Science and Technology of Japan (MEXT).

\section{Conflicts of Interest}

The authors declare no conflicts of interest regarding the publication of this paper.

\section{References}

[1] Gokhberg, M.B., Morgunov, V.A., Yoshino, T. and Tomizawa, I. (1982) Experimental Measurements of Electromagnetic Emissions Possibly Related to Earthquake in Japan. Journal of Geophysical Research, 87, 7824-7828. https://doi.org/10.1029/JB087iB09p07824

[2] Warwick, J.W., Stocker, C. and Meyer, T.R. (1982) Radio Emission Associated with Rock Fracture: Possible Application to the Great Chilean Earthquake of May 22, 1960. Journal of Geophysical Research, 87, 2851-2859. 
https://doi.org/10.1029/JB087iB04p02851

[3] Oike, K. and Ogawa, T. (1986) Electromagnetic Radiations from Shallow Earthquakes Observed in the LF Range. Journal of Geomagnetism and Geoelectricity, 38, 1031-1040. https://doi.org/10.5636/jgg.38.1031

[4] Parrot, M. and Mogilvesky, M.M. (1989) VLF Emissions Associated with Earthquakes and Observed in the Ionosphere and Magnetosphere. Physics of the Earth and Planetary Interiors, 23, 86-99. https://doi.org/10.1016/0031-9201(89)90218-5

[5] Fraser-Smith, A.C., Bernardi, A., McGill, P.R., Ladd, M.E., Helliwell, R.A. and Villard Jr., O.G. (1990) Low Frequency Magnetic Field Measurements near the Epicenter of the $\mathrm{M}=7.1$ Loma Prieta Earthquake. Geophysical Research Letters, 17, 1465-1468. https://doi.org/10.1029/GL017i009p01465

[6] Fujinawa, Y. and Takahashi, K. (1990) Emissions of Electromagnetic Radiation Preceding the Ito Seismic Swarm of 1989. Nature, 347, 376-378. https://doi.org/10.1038/347376a0

[7] Fujinawa, Y. and Takahashi, K. (1994) Anomalous VLF Subsurface Electric Field Changes Preceding Earthquake. In: Hayakawa, M. and Fujinawa, Y., Eds., Electromagnetic Phenomena Related to Earthquake Prediction, Terra Science Publishing Co., Tokyo, 131-148.

[8] Fujinawa, Y. and Takahashi, K. (1995) Electromagnetic Radiations at the Time of the Great Kurile Island Earthquake of 1994. IUGG Meeting, Boulder, CO, 2-14 July 1995.

[9] Molchanov, O.A., Kopytenko, Yu.A., Voronov, P.M., Kopytenko, E.A., Matiashvili, T.G., Fraser-Smith, A.C. and Bernardi, A. (1992) Results of ULF Magnetic Field Measurement Near the Epicenter of Spitak $(M=6.9)$ and Loma Prieta $(M=7)$ Earthquakes: Comparative Analysis. Geophysical Research Letters, 19, 1495-1498. https://doi.org/10.1029/92GL01152

[10] Molchanov, O.A., Mazhaera, O.A., Goliavin, A.N. and Hayakawa, M. (1993) Observation by the Intercosmos-24 Satellite of ELF-VLF Electromagnetic Emissions Associated with Earthquakes. Annals of Geophysics, 11, 431-440.

[11] Molchanov, O.A., Hayakawa, M. and Rafalsky, V.A. (1995) Penetration Characteristics of Electromagnetic Emissions from an Underground Seismic Sources into the Atmosphere, Ionosphere and Magnetosphere. Journal of Geophysical Research, 100, 1691-1712. https://doi.org/10.1029/94JA02524

[12] Varotsos, P., Alexopoulos, K., Lazaridov-Varotsos, M. and Nagao, T. (1993) Earthquake Predictions Issued in Greece by Seismic Electric Signals Since February 6, 1990. Tectonophysics, 224, 269-288. https://doi.org/10.1016/0040-1951(93)90080-4

[13] Hayakawa, M., Molchanov, O.A., Ondoh, T., and Kawai, E. (1996) The Precursory Signature Effect of the Kobe Earthquake in VLF Subionospheric Signal. Journal of the Communications Research Laboratory, 43,169-180. https://doi.org/10.1109/ELMAGC.1997.617080

[14] Hayakawa, M. and Fujinawa, Y. (1994) Electromagnetic Phenomena Related to Earthquake Prediction. Terra Scientific Publishing Company, Tokyo, Japan.

[15] Hayakawa, M. and Molchanov, O.A. (2002) Seismo Electromagnetics: Lithosphere-Atmosphere-Ionosphere Coupling. Terra Scientific Publishing Company, Tokyo, Japan.

[16] Ouzounov, D., Pulinets, S., Hattori, K. and Taylor P. (2018) Pre-Earthquake Processes: A Multidisciplinary Approach to Earthquake Prediction Studies. Geophysical Monograph 234, American Geophysical Union, Washington, DC, and John Wiley and Sons, Inc., Hoboken, NJ. https://doi.org/10.1002/9781119156949 
[17] Singh, B., Kushwah, V., Singh, V. and Tomar, M. (2005) Simultaneous ULF/VLF Amplitude Anomalies Observed During Moderate Earthquakes in Indian Region. Indian Journal of Radio \& Space Physics, 34, 221-232.

[18] Chauhan, V., Singh, O.P., Kushwah, V., Singh, V. and Singh, B. (2009) Ultra Low Frequency (ULF) and Total Electron Content (TEC) Anomalies Observed at Agra and Their Association with Regional Earthquakes. Journal of Geodynamics, 48, 68-74. https://doi.org/10.1016/j.jog.2009.06.002

[19] Kopytenko, Yu.A., Matiashvili, T.G., Voronov, P.M., Kopytenko, F.A. and Molchanov, O.A. (1990) Ultra Low Frequency Emissions Associated with Spitak Earthquake and Following Aftershock Activity Using Geomagnetic Pulsation Data at Observatories Dusheti and Vordziya. Preprint IZMIRAN N3, 888.

[20] Hayakawa, M., Kawate, R., Molchanov, O.A. and Yumoto, K. (1996) Results of Ultra Low Frequency Magnetic Field Measurement during the Guam Earthquake of 8 August 1993. Geophysical Research Letters, 23, 241-244. https://doi.org/10.1029/95GL02863

[21] Gotoh, K., Akinaga, Y., Hayakawa, M. and Hattori, K. (2002) Principal Component Analysis of ULF Geomagnetic Data for Izu Islands Earthquakes in July 2000. Atmospheric Electricity, 22, 1-12. https://doi.org/10.1109/CEEM.2003.237878

[22] Hattori, K., Akinaga, Y., Hayakawa, M., Yumoto, K., Nagao, T. and Uyeda, S. (2002) ULF-magnetic Anomaly Preceding the 1997 Kagoshima Earthquakes. In: Hayakawa, M. and Malchanov, O.A., Eds., Seismo-Electromagnetics: Lithosphere. Atmosphere. Ionosphere Coupling, Terra Scientific Publishing Company, Tokyo, Japan, 19-28.

[23] Hobara, Y., Koons, H.C., Roeder, J.L., Yumoto, K. and Hayakawa, M. (2004) Characteristics of ULF Magnetic Anomaly before Earthquakes. Physics and Chemistry of the Earth, 29, 437-444. https://doi.org/10.1016/j.pce.2003.12.005

[24] Schekotov, A., Fedeorov, E., Hobara, Y. and Hayakawa, M. (2013) ULF Magnetic Field Depression as a Possible Precursor to the 2011/3.11 Japan Earthquake. Atmospheric Electricity, 33, 41-51. https://doi.org/10.1541/jae.33.41

[25] Pulinets, S.A., Legen'ka, A.D. and Alekseev, V.A. (1994) Pre-Earthquake Ionospheric Effects and Their Possible Mechanism. In: Kikuchi, H., Ed., Dusty and Dirty Plasmas, Noise and Chaos in Space and in the Laboratory, Plenum Press, New York, 545-557. https://doi.org/10.1007/978-1-4615-1829-7_46

[26] Hayakawa, M. and Sato, H. (1994) Ionospheric Perturbations Associated with Earthquakes as Detected by Subionospheric VLF Propagation. In: Hayakawa, M. and Fujinawa, Y., Eds., Electromagnetic Phenomena Related to Earthquake Prediction, Terra Scientific Publishing Company, Tokyo, Japan, 391-398.

[27] Hayakawa, M., Hobara, Y., Yamaguchi, H., Ohta, K., Izutsu, J. and Nakamura, T. (2012) A Possible Precursor to the 20113.11 Japan Earthquake: Ionospheric Perturbations as Seen by Subionospheric VLF/LF Propagation. Annals of Geophysics, 55,95-99.

[28] Tatsuta, T., Hobara, Y., Pal, S. and Balikhin, M. (2015) Sub-Ionospheric VLF Signal Anomaly Due to Geomagnetic Storms: A Statistical Study. Annals of Geophysics, 33, 1457-1467. https://doi.org/10.5194/angeo-33-1457-2015

[29] Santosa, H., and Hobara, Y (2017) One Day Prediction of Nighttime VLF Amplitudes Using Nonlinear Autoregression and Neural Network Modeling. Radio Science, 52, 132-145. https://doi.org/10.1002/2016RS006022

[30] Gilbert, F. (1971) Excitation of Normal Modes of the Earth by Earthquake Sources. Geophysical Journal of the Royal Astronomical Society, 22, 223-226. 
https://doi.org/10.1111/j.1365-246X.1971.tb03593.x

[31] Ekstrom, G., Nettles, M. and Dziewonski, A.M. (2012) The Global CMT Project 2004-2010: Centroid-Moment Tensors for 13,017 Earthquakes. Physics of the Earth and Planetary Interiors, 200-201, 1-9. https://doi.org/10.1016/j.pepi.2012.04.002

[32] Ogawa, T., Oike, K. and Miura, T. (1985) Electromagnetic Radiations from Rocks. Journal of Geophysical Research, 90, 6245-6249. https://doi.org/10.1029/JD090iD04p06245

[33] Nitsan, U. (1997) Electromagnetic Emissions Accompanying Fracture of Quartz Bearing Rocks. Geophysical Research Letters, 4, 333-337. https://doi.org/10.1029/GL004i008p00333

[34] Yoshida, S., Clint, O.C. and Sammonds, P.R. (1998) Electric Potential Changes Prior to Shear Fracture in Dry and Saturated Rocks. Geophysical Research Letters, 25, 1577-1580. https://doi.org/10.1029/98GL01222

[35] King, C.Y. (1986) Gas Geochemistry Applied to Earthquake Prediction: An Overview. Journal of Geophysical Research, 91, 12269-12281.

https://doi.org/10.1029/JB091iB12p12269

[36] Kawano, T., Hobara, Y. and Tatsuta, K. (2016) Statistical Study of Seismo-Ionospheric Perturbations around Japan by Using VLF/LF Transmitters with a Focal Mechanism. EGU General Assembly2016, Vienna, Austria, 17-22 April 2016, EPSC2016-17136. 